\title{
ANALISIS KOMPETISI MAKANAN ANTARA IKAN TAWES (Barbonymus gonionotus), IKAN MUJAIR (Oreochromis mossambicus) DAN IKAN NILA (Oreochromis niloticus) DI PERAIRAN WADUK WADASLINTANG KABUPATEN WONOSOBO
}

\author{
Analysis of Food Competition Between Java Barb (Barbonymus gonionotus), Java Tilapia (Oreochromis \\ mossambicus) and Nile Tilapia (Oreochromis niloticus) in Wadaslintang Reservoir, Wonosobo Regency
}

Oleh

Rahanti Kurnia, Niniek Widyorini*), Anhar Solichin

Program Studi Manajemen Sumberdaya Perairan

Departemen Sumberdaya Akuatik Fakultas Perikanan dan Kelautan, Universitas Diponegoro Prof. Soedarto, SH, Tembalang, Semarang, Jawa Tengah - 50275, Telp/Fax. +6224 7474698

Email : rahantikurnia8@gmail.com

\begin{abstract}
ABSTRAK
Ikan tawes (B. gonionotus), ikan mujair (O. mossambicus) dan ikan nila (O. niloticus) merupakan jenis ikan yang terdapat di perairan Waduk Wadaslintang, Kabupaten Wonosobo. Waduk Wadaslintang juga memiliki KJA yang membudidayakan jenis ikan nila (O. niloticus). Berdasarkan jenis ikan yang hidup di Waduk Wadaslintang, maka akan memiliki peluang kompetisi makanan terhadap sumberdaya makanan yang tersedia di perairan. Tujuan penelitian ini adalah untuk mengetahui kebiasaan makanan ikan tawes, ikan mujair dan ikan nila sehingga dapat mengetahui kompetisi makanan yang terdapat di dalamnya, selain itu juga untuk mengetahui kelimpahan jenis plankton di perairan Waduk Wadaslintang. Penelitian dilakukan bulan Mei 2017 di kawasan perairan Waduk Wadaslintang, Kabupaten Wonosobo. Jumlah sampel ikan yang diperoleh 41 ekor. Kelimpahan jenis plankton yang terdapat di perairan Waduk Wadaslintang berkisar antara 424-8376 ind/l dengan jenis fitoplankton yang berasal dari kelas Bacillariophyceae, Chlorophyceae, Cyanophyceae, Xantophyceae dan Zygnematophyceae. Hasil dari perhitungan Index of Preponderance, ikan tawes, ikan mujair dan ikan nila (non KJA) memanfaatkan kelas Bacillariophyceae sebagai makanan utamanya, sedangkan ikan nila (KJA) memanfaatkan pakan buatan yang diduga pelet sebagai makanan utamanya dan kelas Bacillariophyceae sebagai makanan pelengkapnya. Berdasarkan hasil perhitungan tumpang tindih dan luas relung, diketahui beberapa kelompok yang memiliki peluang kompetisi makanan. Kelompok I adalah ikan tawes yang bersifat selektif sehingga tidak memiliki peluang kompetisi makanan, kelompok II adalah ikan mujair dan ikan nila (non KJA) yang memiliki peluang kompetisi tertinggi.
\end{abstract}

Kata Kunci : Kompetisi Makanan; Kelimpahan Plankton; Waduk Wadaslintang

\section{ABSTRACT}

Java barb (B. gonionotus), java tilapia (O. mossambicus) and nile tilapia (O. niloticus) are type of fish contained in the waters of Wadaslintang Reservoir, Wonosobo Regency. Wadaslintang reservoir has a floating net cage (KJA) that cultivate the type of Nile Tilapia (O. niloticus). Based on the type of fish live in Wadaslintang Reservoir it will have a chance of food competition to available food resources in the waters. The research aimed to know food habits Java barb, Java tilapia and Nile tilapia that it can know the food competiton contained in it, moreover that it to know about the abundance of plankton in Wadaslintang reservoir. This research held on May 2017 in the Wadaslintang reservoir, Wonosobo regency. A total of fish is 41. The abundance of plankton in Wadaslintang reservoir ranged between 424-8376 ind/L with the type of phytoplankton derived from Bacillariophyceae, Chlorophyceae, Cyanophyceae, Xantophyceae and Zygnematophyceae. The result from Index of Preponderance of java barb, java tilapia and nile tilapia (non KJA) utilized Bacillariophyceae as the main food, while nile tilapia (KJA) utilized an artificial feeds which is supposed to pellets as the main food and Bacillariophyceae as the complementary food. Based on niche overlap, there are some groups have an opportunities for food competition. First group is Java barb that haven't an opportunities for food competition because java barb is a selective fish, second group are Java tilapia and nile tilapia (non KJA) have a highest opportunities for food competition.

Keywords : Food Competition; Plankton Abundance; Wadaslintang Reservoir

*) Penulis Penanggungjawab 


\section{PENDAHULUAN}

Waduk Wadaslintang merupakan salah satu wilayah perairan yang memiliki sumberdaya ikan yang melimpah, sehingga banyak pengunjung yang datang berkunjung untuk memancing. Waduk sebagai sarana perikanan dan obyek pariwisata juga dapat menghasilkan pemasukan yang cukup berarti bagi masyarakat disekitarnya. Budidaya KJA yang dilakukan di perairan Waduk Wadaslintang dilakukan secara intensif yaitu dengan menggunakan pakan tambahan dengan kadungan protein $28 \%$. Ikan yang dibudidayakan di Waduk Wadaslintang biasanya merupakan jenis ikan yang tahan terhadap perubahan lingkungan serta mudah dalam pemanfaatan pakannya. Salah satu ikan yang dibudidayakan adalah ikan nila. Ikan nila yang dibudidayakan juga memiliki ukuran yang bervariasi. (Widyastuti et al, 2009).

Ketersediaan makanan di suatu perairan merupakan faktor yang mempengaruhi besar kecilnya populasi ikan di perairan tersebut. Makanan yang dimakan oleh ikan dapat berupa fitoplankton, zooplankton, benthos atau ikan kecil lainnya. Kebiasaan makanan ikan (food habits) adalah kuantitas dan kualitas makanan yang dimakan oleh ikan, sedangkan kebiasaan cara memakan (feeding habits) adalah waktu, tempat dan caranya makanan itu didapatkan oleh ikan. Kebiasaan makanan dan cara memakan ikan secara alami bergantung pada lingkungan tempat ikan hidup. Salah satu tujuan kebiasaan makanan (food habits) ikan dimaksudkan untuk mengetahui pakan yang dimakan oleh setiap jenis ikan. (Anisa et al, 2015).

Ikan tawes, ikan mujair dan ikan nila merupakan salah satu jenis ikan herbivora yang menjadikan tumbuhan air, lumut, dan fitoplankton sebagai pakan alaminya. Perairan di Waduk Wadaslintang merupakan perairan yang subur karena banyaknya komposisi fosfat $(\mathrm{P})$ dan nitrat $(\mathrm{N})$ yang berasal dari KJA maupun dari kotoran-kotoran ikan yang berasal dari pakan KJA. Keramba Jaring Apung (KJA) di perairan Waduk Wadaslintang juga akan berpengaruh pada kebiasaan makanan ikan yang ada di dalamnya, sehingga akan terlihat perbedaan kebiasaan makanan pada jenis ikan yang berada di luar KJA dan ikan yang berada di dalam KJA. (Sulardiono, 2009).

Tujuan penelitian ini adalah sebagai berikut :

1. Mengetahui kebiasaan makanan ikan tawes, ikan mujair dan ikan nila yang ditemukan di Waduk Wadaslintang dan yang ada di KJA,

2. Mengetahui kelimpahan jenis plankton yang ada di perairan Waduk Wadaslintang; dan

3. Mengetahui kompetisi makan ikan nila, ikan tawes dan ikan mujair yang ada di luar KJA.

\section{MATERI DAN METODE PENELITIAN}

\section{Materi}

Materi pada penelitian ini adalah ikan tawes (Barbonymus gonionotus), ikan mujair (Oreochromis mossambicus) dan ikan nila (Oreochromis niloticus). Alat yang digunakan adalah satu buah section kit digunakan untuk membedah ikan; gelas ukur volume $100 \mathrm{ml}$; beaker glass volume $500 \mathrm{ml}$ sebagai wadah isi usus yang sudah diencerkan; batang pengaduk sebagai alat homogenisasi; pipet tetes digunakan untuk mengambil isi usus; Sedgwick rafter sebagai wadah untuk meletakkan sampel isi usus dan mikroskop untuk mengamati sampel.

\section{Metode Penelitian}

Penelitian ini dilakukan dengan mengambil sampel ikan tawes, ikan mujair dan ikan nila yang diperoleh dari hasil sampling dengan jaring insang sebanyak 2 kali sampling (satu minggu sekali). Sampel yang diambil dari setiap titik merupakan sampel air dan sampel ikan. Banyaknya sampel ikan diambil dari setiap kali melakukan penangkapan pada satu kali melakukan sampling. Penentuan titik sampling dipilih dari lokasi ikan yang tertangkap pada jaring. Lokasi sampling dilakukan pada lima titik lokasi sampling dan terdapat satu titik lokasi sampling yang terdapat di KJA (pada lokasi ini hanya terdapat satu KJA).

Data yang digunakan adalah dengan cara membedah sampel ikan dan diambil ususnya kemudian diawetkan dengan formalin $4 \%$. Usus yang sudah diawetkan, kemudian isi usus dikeluarkan dan diencerkan dengan aquadest. Langkah selanjutnya, dilakukan identifikasi isi lambung dengan meletakkan sampel yang sudah diencerkan dengan menggunakan pipet tetes dan dituangkan ke dalam Sedgwick Rafter. Kemudian dilakukan pengamatan dibawah mikroskop. Metode identifikasi jenis plankton dengan menggunakan metode check list yaitu dengan mencocokkan jenis plankton yang ditemukan dengan gambar yang terdapat pada buku identifikasi plankton. Identifikasi plankton menggunakan buku identifikasi oleh Edmonson (1959) yang berjudul Fresh Water Biology dan buku identifikasi oleh Hilary Belcher dan Erica Swale (1976) yang berjudul A Beginner's Guide to Freshwater Algae. Jenis plankton yang ada kemudian dicatat, dihitung jumlahnya dan dikelompokkan sesuai dengan jenis yang ditemukan. Perhitungan untuk analisis tumpang tindih di analisa dengan menggunakan aplikasi SPSS.

\section{Analisis Data}

\section{Analisis Index of Preponderance}

Perhitungan Index of Preponderance bertujuan untuk mengetahui jenis-jenis makanan apa saja yang dimakan oleh ikan serta dapat mengetahui makanan utama, pelengkap, dan makanan tambahan atau makanan pengganti ikan. Menurut Effendi (1997) diperoleh dengan formula sebagai berikut : 
Keterangan :

$$
\mathrm{IP}=\frac{N i \times O i}{\sum N i \times O i} \times 100 \%
$$

\section{IP = Index of Preponderance}

$\mathrm{Ni}=$ Persentase jumlah satu macam makanan

Oi $\quad=$ Persentase frekuensi kejadian satu macam makanan

Berdasarkan nilai IP yang diperoleh, maka urutan makanan ikan dapat dibedakan dalam tiga kategori berdasarkan persentase Index of Preponderance (IP) yaitu :

$\begin{array}{ll}\text { IP }>40 \% & : \text { Makanan utama } \\ 4 \%<\text { IP }<40 \% & : \text { Makanan pelengkap } \\ \text { IP }<4 \% & : \text { Makanan tambahan }\end{array}$

\section{Analisis Kelimpahan Plankton Perairan}

Perhitungan jumlah plankton dilakukan dibawah mikroskop dengan menggunakan Sedgwick Rafter sebagai wadah untuk pengamatan sampel dibawah mikroskop. Menurut APHA (2005) dalam Nurfadilah et al, (2012) diperoleh dengan formla sebagai berikut :

$$
N=n \times \frac{a \times v \times 1}{A \times v c \times V}
$$

Keterangan :

$\begin{array}{ll}\mathrm{N} & =\text { Kelimpahan plankton per liter } \\ \mathrm{n} & =\text { Jumlah plankton yang tercacah } \\ \mathrm{a} & =\text { Luas penampang }\left(\mathrm{mm}^{2}\right) \\ \mathrm{V} & =\text { Volume air yang tersaring }(\mathrm{ml}) \\ \mathrm{A} & =\text { Luas satu lapangan pandang }\left(\mathrm{mm}^{2}\right) \\ \mathrm{vc} & =\text { Volume air pada penampang }(\mathrm{ml}) \\ \mathrm{V} & =\text { Volume air yang disaring }\end{array}$

\section{Analisis Indeks Pilihan Makanan}

Perhitungan indeks pemilihan makanan dilakukan dengan membandingkan sumberdaya makanan yang ada pada lambung ikan dengan sumberdaya yang ada dalam perairan. Perhitungan indeks ini menggunakan metode yang dikembangkan oleh Krebs (1989) dalam Simbolon et al, (2010), dengan rumus :

Keterangan :

$$
E=\frac{r_{i}-p_{i}}{r_{i}+p_{i}}
$$

$\mathrm{E} \quad=$ Indeks pilihan jenis makanan (Index of Selectivity)

$\mathrm{r}_{\mathrm{i}} \quad$ = Persentase pakan alami yang terdapat pada usus ikan

$\mathrm{p}_{\mathrm{i}} \quad=$ Persentase pakan alami yang terdapat di perairan

Indeks E berkisar dari +1 hingga -1. Apabila nilai E positif, maka terjadi pemilihan pakan terhadap pakan alami yang dimaksud. Apabila nilai E negatif, maka tidak terjadi pemilihan terhadap pakan yang dimaksud. Harga $\mathrm{E}=0$, berarti tidak adanya pemilihan ikan terhadap pakan alami yang ada di ususnya.

\section{Analisis Luas Relung}

Luas relung digunakan untuk mengetahui bagaimana selektivitas kelompok jenis ikan terhadap makanannya. Luas relung dilihat berdasarkan makanan yang dikonsumsi oleh ikan dan dihitung dengan rumus yang dikemukakan oleh Tjahjo (2000) dalam Tresna et al, (2012) sebagai berikut :

Keterangan :

$$
B_{i}=\frac{\mathbf{1}}{\sum P i^{2}}
$$

$\mathrm{Bi} \quad=$ Luas relung makanan

$\mathrm{Pi} \quad=$ Proporsi jenis ikan yang berhubungan dengan jenis makanan

Tidak ada kriteria nilai luas relung, karena ikan yang memiliki nilai luas relung yang luas berarti ikan tersebut memanfaatkan makanan yang tersedia dalam jumlah yang besar. Ikan yang memiliki nilai luas relung yang sempit berarti ikan tersebut selektif dalam memilih makanan yang tersedia di perairan (spesialis).

\section{Analisis Kompetisi Makan}

Nilai tumpang tindih relung makanan menunjukkan adanya kesamaan jenis makanan yang dimanfaatkan oleh ikan, baik berdasarkan jenis kelamin maupun kelompok ukuran ikan atau kelompok jenis lainnya. Tumpang tindih relung makanan akan menyebabkan adanya persaingan (kompetisi) makanan antar penghuni relung. Tumpang tindih relung makanan antar 
jenis ikan dilakukan dengan menggunakan metode Simples of The Available Index oleh Krebs, (1989) dalam Sulistiono et al, (2009) yaitu :

Keterangan :

$$
C_{h}=\frac{2 \sum P i j \cdot P i k}{\sum P i j^{2}+\sum P i k^{2}}
$$

Cih = Tumpang tindih relung makanan antar jenis ikan ke-i dengan jenis ke- $\mathrm{h}$

Pik = Proporsi jenis ikan ke-i yang berhubungan dengan sumberdaya makanan ke-k

$\mathrm{Phj}=$ Proporsi jenis ikan ke-h yang berhubungan dengan sumberdaya makanan ke-j

Nilai tumpang tindih relung makanan yang mendekati nilai satu (1) menunjukkan adanya kompetisi yang tinggi antar dua jenis ikan yang dianalisis. Tumpang tindih relung makanan terjadi bila ada kesamaan jenis makanan yang dimanfaatkan oleh dua jenis atau lebih kelompok ikan. Sebaliknya, jika mendekati nol (0), artinya tidak diperoleh jenis makanan yang sama.

\section{HASIL DAN PEMBAHASAN}

Hasil

Deskripsi Lokasi

Waduk Wadaslintang memiliki fungsi utama sebagai sarana pembangkit listrik tenaga air dan sebagai pengairan untuk irigasi di sekitar waduk. Waduk Wadaslintang mengairi lahan irigasi dengan pola tanam padi-palawija setiap tahun. Beberapa fungsi Waduk Wadaslintang yang lain adalah sebagai penampung air, pencegah banjir, pariwisata dan bidang perikanan. Pada bidang perikanan, adanya penangkapan ikan oleh para nelayan dan budidaya Keramba Jaring Apung (KJA).

Nelayan merupakan salah satu pekerjaan utama sebagian besar masyarakat di sekitar Waduk Wadaslintang. Nelayan Waduk Wadaslintang dalam melakukan penangkapan menggunakan jaring insang. Jaring akan ditebar pada pagi hari dan sore hari. Jaring insang yang digunakan oleh nelayan Waduk Wadaslintang memiliki panjang yang beragam yaitu berkisar antara 5-15 meter. Jaring yang digunakan oleh nelayan Waduk Wadaslintang memiliki ukuran mata jaring yang beragam dengan ukuran mulai dari $0,75-4,5$ inchi. Operasional jaring dilakukan dengan posisi melintang pada kedalaman berkisar antara 2-5 meter.

\section{Jumlah Ikan di Perairan Waduk Wadaslintang}

Jumlah ikan yang tertangkap pada saat sampling di Perairan Waduk Wadaslintang dengan menggunakan jaring insang pada jenis ikan tawes (B. gonionotus), ikan mujair (O. mossambicus) dan ikan nila (O. niloticus) dapat dilihat pada Tabel 1.

Tabel 1. Jumlah Ikan di Perairan Waduk Wadaslintang

\begin{tabular}{|c|c|c|c|}
\hline No. & Jenis Ikan & Jumlah Ikan & Persentase $(\%)$ \\
\hline 1. & Tawes (Barbonymus gonionotus) & 14 & 34,14 \\
\hline 2. & Mujair (Oreochromis mossambicus) & 9 & 22 \\
\hline 3. & Nila Non KJA (Oreochromis niloticus) & 15 & 36,58 \\
\hline \multirow[t]{2}{*}{4.} & Nila KJA (Oreochromis niloticus) & 3 & 7,31 \\
\hline & & 41 & 100 \\
\hline
\end{tabular}

Dari hasil tabel, diketahui ikan tawes yang tertangkap di perairan Waduk Wadaslintang pada saat penelitian adalah 14 ekor atau $34,14 \%$. Ikan mujair yang tertangkap pada saat penelitian adalah 9 ekor atau $22 \%$ dan ikan nila yang tertangkap pada saat penelitian berjumlah 18 ekor, dimana ikan nila diluar KJA adalah 15 ekor dengan persentase $36,58 \%$ dan ikan nila di dalam KJA adalah 3 ekor dengan persentase 7,31\%. Ikan nila merupakan jenis ikan yang dibudidayakan di KJA Waduk Wadaslintang, sehingga tidak ditemukan jenis ikan lain pada KJA. Total ikan yang tertangkap pada saat sampling penelitian di perairan Waduk Wadaslintang adalah 41 ekor.

\section{Perhitungan Index of Preponderance (IP)}

a. Perhitungan Index of Preponderance Pada Usus Ikan Tawes, Ikan Mujair dan Ikan Nila (non KJA)

Perhitungan IP dilakukan pada usus ikan dari tiap jenis ikan tawes, ikan mujair dan ikan nila yang tertangkap. Ikan nila diambil dari dua habitat yang berbeda, yaitu yang berada di Keramba Jaring Apung (KJA) dan yang berada di luar KJA. Jumlah ikan tawes yang diamati adalah sebanyak 14 ekor, ikan mujair sebanyak 9 ekor, ikan nila di luar KJA sebanyak 15 ekor dan ikan nila yang berada di KJA sebanyak 3 ekor. Perhitungan Index of Preponderance ikan tawes, ikan mujair dan ikan nila tersaji pada Tabel 2. 
Tabel 2. Perhitungan Index of Preponderance Pada Usus Ikan Tawes, Ikan Mujair dan Ikan Nila (Non KJA)

\begin{tabular}{|c|c|c|c|c|}
\hline \multirow[b]{2}{*}{ No } & \multirow[b]{2}{*}{ Jenis Plankton } & \multicolumn{3}{|c|}{ Index of Preponderance (IP) } \\
\hline & & Tawes (\%) & Mujair (\%) & $\begin{array}{c}\text { Nila (Non KJA) } \\
(\%)\end{array}$ \\
\hline \multirow[t]{12}{*}{1.} & Bacillariophyceae & 70,5 & 56 & 62.1 \\
\hline & - Centronella & 0,082 & 7,4 & 0 \\
\hline & - Diadesmis & 11,65 & 0 & 7,6 \\
\hline & - Fragilaria & 5,25 & 9,1 & 0 \\
\hline & - Gyrosigma & 5,58 & 0 & 9 \\
\hline & - Mastogloia & 0 & 0 & 2,7 \\
\hline & - Navicula & 28,4 & 7,4 & 0 \\
\hline & - Nitzschia & 3,61 & 12,3 & 6,7 \\
\hline & - Pinnularia & 3,44 & 19,5 & 26,3 \\
\hline & - Rhizosolenia & 6,24 & 0 & 1,6 \\
\hline & - Surirella & 0,49 & 0 & 7,8 \\
\hline & - Synedra & 5,74 & 0 & 0 \\
\hline \multirow[t]{4}{*}{2.} & Chlorophyceae & 12,31 & 1,6 & 19,1 \\
\hline & - Cladophora & 0 & 0,4 & 0 \\
\hline & - Pandorina & 0 & 1,1 & 0 \\
\hline & - Radiofilum & 12,31 & 0 & 19,1 \\
\hline \multirow[t]{3}{*}{3.} & Cyanophyceae & 13,8 & 22,1 & 16,2 \\
\hline & - Gomphosphaeria & 2,79 & 10,1 & 8,5 \\
\hline & - Oscillatoria & 11 & 11,9 & 7,6 \\
\hline \multirow[t]{5}{*}{4.} & Zygnematophyceae & 3,4 & 20,3 & 2,6 \\
\hline & - Gonatozygon & 0,24 & 10,7 & 2,6 \\
\hline & - Mougeotia & 3,12 & 9,4 & 0 \\
\hline & - Straurastrum & 0 & 0,07 & 0 \\
\hline & & 100 & 100 & 100 \\
\hline
\end{tabular}

Berdasarkan tabel 2, diketahui bahwa kelas Bacillariophyceae merupakan kelas yang merupakan makanan utama dari ikan tawes, ikan mujair dan ikan nila (non KJA). Ikan tawes dan ikan nila (non KJA) memanfaatkan kelas Chlorophyceae dan kelas Cyanophyceae sebagai makanan pelengkap dan kelas Zygnematophyceae sebagai makanan tambahan. Pada ikan mujair, memanfaatkan kleas Cyanophyceae dan kelas Zygnematophyceae sebagai makanan pelengkap dan kelas Chlorophyceae sebagai makanan tambahan.

\section{b. Perhitungan Index of Preponderance Pada Usus Ikan Nila (KJA)}

Sampel ikan nila diambil dari dua habitat yang berbeda. Habitat yang berada di luar KJA dan di dalam KJA. Perbedaan habitat tersebut akan berpengaruh terhadap kebiasaan makanannya. Ikan nila yang berada di KJA, akan diberi pakan secara khusus oleh pembudidaya. Salah satu jenis makanan yang diberikan oleh pembudidaya untuk ikan nila di dalam KJA, biasanya berupa pakan buatan (pellet). Makanan yang terdapat di dalam usus ikan nila di dalam KJA, terdiri jenis makanan yang berbeda dari ikan nila yang berada di luar KJA. Perhitungan Index of Preponderance pada usus ikan nila di dalam KJA dengan jumlah ikan yang diamati sebanyak 3 ekor disajikan pada Tabel 3.

Tabel 3. Perhitungan Index of Preponderance (IP) Pada Usus Ikan Nila di dalam KJA

\begin{tabular}{llc}
\hline \multirow{2}{*}{ No Jenis Plankton } & $\begin{array}{c}\text { Index of Preponderance } \\
(\mathbf{\%})\end{array}$ \\
\hline 1. & Bacillariophyceae & $\mathbf{1 3 , 8}$ \\
& - Centronella & 3,7 \\
& - Nitzschia & 2,5 \\
2. Pinnularia & Chlorophyceae & 7,4 \\
& - Pleurococcus & $\mathbf{2 6 , 8}$ \\
& - Radiofilum & 12,9 \\
3. & Zygnematophyceae & 13,7 \\
& - Meogeutia & $\mathbf{4 , 2}$ \\
4. $\quad$ Tidak Teridentifikasi & 4,2 \\
\hline & Jumlah & $\mathbf{5 3}$ \\
\hline
\end{tabular}


Berdasarkan Tabel 3 ikan nila (KJA) lebih banyak mengonsumsi jenis tidak teridentifikasi yang diduga sebagai pakan buatan (pellet). Persentase jenis tidak teridentifikasi yang dikonsumsi oleh ikan nila (KJA) mencapai lebih dari $40 \%$, sehingga jenis tidak teridentifikasi dikategorikan sebagai makanan utama ikan nila (KJA). Selain memanfaatkan jenis tidak teridentifikasi, yang diduga pakan buatan (pellet) sebagai makanan utama. Berdasarkan kategori persentase Index of Preponderance, kelas Bacillariophyceae, kelas Chlorophyceae dan kelas Zygnematophyceae yang dikonsumsi oleh ikan nila (KJA), merupakan makanan pelengkap. Hal ini dikarenakan persentase makanan kurang dari $40 \%$ tetapi tidak kurang dari $4 \%$. Ikan nila (KJA), tidak mengonsumsi pakan alami sebagai makanan tambahannya. Berdasarkan hasil perhitungan Index of Preponderance, tidak ditemukan jenis makanan yang dikonsumsi dengan persentase kurang dari $4 \%$.

\section{Kelimpahan Plankton di Perairan Waduk Wadaslintang}

Plankton merupakan salah satu jenis makanan alami yang tersedia di perairan. Kelimpahan plankton yang terdapat di perairan Waduk Wadaslintang berdasarkan kelas fitoplankton tersaji pada Tabel 4.

Tabel 4. Kelimpahan Plankton di Perairan Waduk Wadaslintang

\begin{tabular}{llcc}
\hline No. & Jenis Plankton & Jumlah (ind/l) & Persentase (\%) \\
\hline 1. & Bacillariophyceae & 8.376 & 50,63 \\
2. & Chlorophyceae & 2.864 & 17,60 \\
3. & Cyanophyceae & 1.968 & 11,90 \\
4. & Xantophyceae & 424 & 2,56 \\
5. & Zygnematophyceae & 2.912 & 17,31 \\
\hline & & 16.544 & 100
\end{tabular}

Waduk Wadaslintang ditemukan beberapa jenis plankton dengan kelimpahan antara 424-8376 ind/L, diduga bahwa jumlah dari suatu jenis plankton yang ada di perairan menandakan bahwa jumlah makanan alami untuk biota perairan tersebut melimpah. Berdasarkan hasil sampling, didapatkan lima kelas plankton yang berbeda yaitu kelas Bacillariophyceae, kelas Chlorophyceae, kelas Cyanophyceae, kelas Xantophyceae dan kelas Zygnematophyceae. Kelas Bacillariophyceae terdapat pada semua stasiun.

\section{Perhitungan Indeks Pilihan Makanan}

Indeks pilihan makanan merupakan perhitungan dengan melakukan sebuah perbandingan, antara isi makanan yang terdapat di usus ikan dengan makanan yang tersedia di perairan. Perhitungan indeks pilihan makanan pada usus ikan tawes, ikan mujair dan ikan nila (non KJA) tersaji pada Tabel 5.

Tabel 5. Perhitungan Indeks Pilihan Makanan Pada Usus Ikan Tawes, Ikan Mujair dan Ikan Nila (Non KJA)

\begin{tabular}{llccc}
\hline \multirow{2}{*}{ No } & \multirow{2}{*}{ Jenis Plankton } & \multicolumn{3}{c}{ Indeks Pilihan Makanan (E) } \\
\cline { 3 - 5 } & & Tawes & Mujair & Nila (Non KJA) \\
\hline 1. & Bacillariophyceae & 0,16 & 0,04 & 0,09 \\
2. & Chlorophyceae & $-0,17$ & $-0,79$ & 0,02 \\
3. & Cyanophyceae & 0,06 & 0,29 & 0,12 \\
4. & Xantophyceae & -1 & -1 & -1 \\
5. & Zygnematophyceae & $-0,66$ & 0,07 & $-0,55$ \\
\hline
\end{tabular}

Pemilihan makanan pada ikan tawes (B. gonionotus), ikan mujair (O. mossambicus) dan ikan nila $(O$. niloticus) non KJA memiliki kegemaran pakan alami yang berbeda. Ikan tawes, ikan mujair dan ikan nila (non KJA) memilih kelas Cyanophyceae, kelas Chlorophyceae, kelas Zygnematophyceae dan kelas Bacillariophyceae sebagai makanan yang digemari. Pada ketiga jenis ikan, kelas Xantophyceae merupakan kelompok makanan yang sama sekali tidak digemari ikan sebagai makanannya. Pemanfaatan pakan alami oleh ikan tawes, ikan mujair dan ikan nila (non KJA) lebih cenderung menyukai kelas Bacillariophyceae.

\section{Analisis Luas Relung}

Perhitungan luas relung pada ikan untuk mengetahui seberapa besar ikan dalam memanfaatkan makanannya dan mengetahui selektivitas jenis dalam kelompoknya. Luas relung dapat diketahui dengan mengetahui jenis makanan yang dimakan oleh ikan tersebut. Perhitungan luas relung ikan tawes, ikan mujair dan ikan nila tersaji pada Tabel 6 berikut 
Tabel 6. Perhitungan Luas Relung Ikan di Perairan Waduk Wadaslintang

\begin{tabular}{|c|c|c|c|c|c|c|c|}
\hline \multirow{2}{*}{ No } & \multirow{2}{*}{ Jenis Ikan } & \multicolumn{4}{|c|}{$\mathbf{P i}^{2}$} & \multirow{2}{*}{$\begin{array}{c}\text { Jumlah } \\
\left(\sum \mathbf{P i}^{2}\right)\end{array}$} & \multirow{2}{*}{$\begin{array}{l}\text { Luas Relung } \\
\qquad\left(\sum \mathbf{P i}^{2}\right)^{-1}\end{array}$} \\
\hline & & Bacilla & Chloro & Cyano & Zygnema & & \\
\hline 1. & Tawes & 0,497 & 0,015 & 0,019 & 0,001 & 0,532 & 1,878 \\
\hline 2. & Mujair & 0,313 & 0,0002 & 0,048 & 0,041 & 0,403 & 2,475 \\
\hline 3. & Nila (Non KJA) & 0,385 & 0,036 & 0,026 & 0,0006 & 0,449 & 2,226 \\
\hline
\end{tabular}

Luas relung yang terdapat pada ikan tawes, ikan mujair dan ikan nila (non KJA) adalah 1,878-2,475. Ikan tawes memiliki nilai luas relung paling kecil, sehingga ikan tawes merupakan salah satu jenis ikan yang selektif terhadap makanannya. Ikan mujair memiliki nilai luas relung yang paling besar. Pemanfaatan makanan oleh ikan mujair lebih banyak pada kelas Bacillariophyceae yang ditemukan pada ususnya.

\section{Analisis Kompetisi Makanan}

Kompetisi makanan pada ikan dihitung dengan melihat tumpang tindih makanan yang ada pada usus ikan sehingga dapat menunjukkan adanya kesamaan jenis makanan yang dimanfaatkan oleh ikan. Tumpang tindih relung makanan yang akan menyebabkan kompetisi antar penghuni perairan. Perhitungan tumpang tindih tersaji pada Tabel 7 berikut

Tabel 7. Luas Relung dan Tumpang Tindih Relung Makanan Ikan di Perairan Waduk Wadaslintang

\begin{tabular}{cccccc}
\hline \multirow{2}{*}{ No. } & Jenis Ikan & Luas Relung & \multicolumn{3}{c}{ Tumpang Tindih } \\
\cline { 3 - 5 } & & 1,878 & Tawes & Mujair & Nila (Non KJA) \\
\hline 1. & Tawes & 1 & & \\
2. & Mujair & 2,475 & 0,963 & 1 & \\
3. & Nila ( Non KJA) & 2,226 & 0,985 & 0,994 & 1
\end{tabular}

Tumpang tindih atau niche overlap terjadi apabila terdapat dua jenis ikan atau lebih memanfaatkan sumberdaya makanan yang sama. Nilai tumpang tindih relung makanan menunjukkan adanya kesamaan jenis makanan yang dimanfaatkan diantara kelompok ikan.

\section{Pembahasan}

Jumlah Ikan di Perairan Waduk Wadaslintang

Jumlah ikan yang tertangkap di perairan Waduk Wadaslintang di dominasi oleh ikan nila di luar KJA sebanyak 15 ekor. Berdasarkan waktu sampling, ikan nila mudah di dapatkan pada saat pagi hari dan sore hari, sedangkan untuk ikan tawes dan ikan mujair lebih banyak didapatkan pada saat penangkapan dilakukan pagi hari. Menurut Fatah dan Susilo (2015), ikan nila merupakan salah satu ikan yang paling mendominasi hasil tangkapan di Waduk Wadaslintang. Hal ini dikarenakan melimpahnya sumberdaya makanan yang ada di Waduk Wadaslintang dengan sifat ikan nila yang mudah menyesuaikan diri dengan keadaan di perairan sekitarnya. Hasil tangkapan dapat dipengaruhi dari waktu-waktu tertentu pada saat penangkapan. Ikan nila mudah didapatkan pada saat penangkapan pagi hari dan sore hari. Beberapa ikan lainnya, lebih mudah ditangkap pada saat pagi hari, seperti ikan tawes. Hal ini dapat disebabkan karena kebiasaan makan dan kelimpahan sumberdaya makanan yang ada di perairan tersebut.

\section{Perhitungan Index of Preponderance (IP)}

\section{a. Perhitungan Index of Preponderance Pada Usus Ikan Tawes, Ikan Mujair dan Ikan Nila (non KJA)}

Pemanfaatan jenis plankton oleh ikan tawes (B. gonionotus), ikan mujair $(O$. mossambicus $)$ dan ikan nila $(O$. niloticus) berbeda satu sama lain yang dapat dilihat dari isi usus ikan tersebut. Ikan tawes memanfaatkan kelas Bacillariophyceae sebagai makanan utama, karena termasuk kelompok makanan yang dimanfaatkan memiliki persentase IP lebih dari $40 \%$. Habitat ikan tawes yang hidup pada daerah seperti rawa, danau atau sungai. Ikan tawes lebih banyak 
memanfaatkan jenis fitoplankton. Hal ini diperkuat oleh Hedianto et al, (2013), Ikan tawes tergolong herbivora dengan makanan utama berupa tumbuhan atau fitoplankton. Ikan tawes lebih banyak memanfaatkan fitoplankton dari kelas Bacillariophyceae dengan genus yang dominan ditemukan adalah Navicula sp.

Ikan mujair memanfaatkan kelas Bacillariophyceae sebesar 56\%, sehingga dapat dikategorikan sebagai makanan utama. Ikan mujair termasuk jenis ikan herbivora cenderung omnivora. Ikan mujair memanfaatkan jenis-jenis dari tumbuhan air, lumut-lumutan dan beberapa jenis crustacea renik. Menurut Ghufron dan Kordi (2005) Ikan mujair memakan tumbuhan air, diatom, beberapa jenis dari Zygnematophyceae, Bacillariophyceae, Cyanophyceae, Chlorophyceae dan Dinophyceae. Kelas dari Bacillariophyceae merupakan salah satu yang bisa digemari karena melimpahnya di suatu perairan. Ikan mujair akan memakan beberapa jenis dari zooplankton atau jenis-jenis dari crustacean renik apabila fitoplankton tidak melimpah di perairan tersebut.

Ikan nila (non KJA) lebih memanfaatkan kelas Bacillariophyceae sebagai makanan utama. Kelas Chlorophyceae, dan kelas Cyanophyceae sebagai makanan pelengkap dan kelas Zygnematophyceae sebagai makanan tambahan pada ikan nila (non KJA). Berdasarkan kategori urutan makanan, ikan nila (non KJA) memanfaatkan kelas Bacillariophyceae sebesar $62,1 \%$ sehingga dapat dikategorikan sebagai makanan utama. Ikan nila merupakan salah satu jenis ikan yang bersifat herbivora cenderung omnivora. Ikan nila cenderung akan memanfaatkan jenis makanan yang ada di sekitarnya. Menurut Pratiwi et al, (2013), Stasiun KJA dan non-KJA memiliki komposisi genera yang mirip. Hal ini diduga lokasi kedua stasiun yang cenderung berpengaruh dari adanya lokasi persawahan di sekitar stasiun non-KJA dan adanya operasi pemeliharaan ikan di stasiun KJA. Kelas Bacillariophyceae merupakan salah satu yang terbanyak dan melimpah karena adanya masukkan bahan organik, sehingga ikan nila lebih memanfaatkan Bacillariophyceae sebagai makanan utama. Karena ikan nila memiliki sifat herbivora yang cenderung memanfaatkan segala yang ada di sekitarnya atau yang lebih melimpah pada perairan tersebut.

\section{b. Perhitungan Index of Preponderance Pada Usus Ikan Nila (KJA)}

Berdasarkan hasil yang telah didapatkan, ikan nila di dalam KJA memanfaatkan kelompok makanan jenis tidak teridentifikasi yang diduga sebagai pakan buatan (pellet). Pemanfaatan jenis tersebut dengan persentase 53\% dikategorikan sebagai makanan utama. Adanya pakan buatan tersebut menjadikan melimpahnya jenis dari kelas Chlorophyceae pada perairan KJA. Pakan buatan memiliki komposisi unsur zat hara tertentu menyebabkan perubahan pada kesuburan perairan. Hal ini dapat berpengaruh terhadap kelimpahan Chlorophyceae. Menurut Setijaningsih (2011), Tinggi atau rendahnya komposisi pakan buatan (pellet) mengakibatkan pertumbuhan komunitas atau jenis fitoplankton tertentu. Fitoplankton dari jenis Zygnematophyceae dan Bacillariophyceae dapat tumbuh bagus pada pakan buatan (pellet) dengan rasio yang rendah, sedangkan jenis Chlorophyceae pada pakan buatan (pellet) dengan rasio sedikit lebih tinggi. Adanya zat unsur hara yang terdapat pada pellet (N, P dan K) di KJA merupakan salah satu faktor dimana perairan dapat berubah menjadi subur, sehingga perairan menjadi eutrofik.

\section{Kelimpahan Plankton di Perairan Waduk Wadaslintang}

Berdasarkan hasil yang telah didapatkan Kelas Bacillariophyceae terdapat pada semua stasiun. Jenis yang paling mendominasi dari kelas Bacillariophyceae adalah Navicula. Menurut Nurfadillah et al, (2012), Kelas Bacillariophyceae merupakan jenis diatom yang paling toleran terhadap kondisi perairan seperti halnya suhu. Mampu beradaptasi dengan baik pada perairannya, sehingga dapat berkembang biak dengan cepat dan memanfaatkan kandungan nutrient dengan baik.

\section{Perhitungan Indeks Pilihan Makanan}

Pemanfaatan pakan alami oleh ikan tawes, ikan mujair dan ikan nila (non KJA) lebih cenderung menyukai kelas Bacillariophyceae. Hal ini dikarenakan adanya pasokan unsur hara yang mendukung pakan alami dari kelas Bacillariophyceae untuk berkembang biak. Menurut Tresna et al, (2012) Kesukaan ikan terhadap makanannya sangat relatif karena belum tentu suatu jenis makanan melimpah di perairan dapat dimanfaatkan oleh ikan. Beberapa faktor yang dapat menyebabkan hal tersebut seperti penyebaran organisme yang tidak merata sebagai makanan ikan, ketersediaan makanan, pilihan dari ikan tersebut, serta adanya faktor fisik dan kimia perairan yang dapat mempengaruhi perubahan suatu kondisi perairan.

\section{Analisis Luas Relung}

Berdasarkan hasil yang didapatkan, tinggi rendahnya nilai luas relung makanan menunjukkan tingkat generalitas ikan dalam memanfaatkan pakan alami yang ada. Menurut Elinah et al, (2016) Sifat selektif ikan dapat terlihat pada satu jenis ikan karena hanya memanfaatkan beberapa jenis makanan dengan persentase yang tinggi. Ikan yang memanfaatkan berbagai macam sumberdaya makanan sebagai makanannya maka luas relungnya akan meningkat meskipun sumberdaya yang tersedia menurun. Sifat generalis suatu jenis ikan memanfaatkan pakan alami dalam sumberdaya makanannya akan meningkatkan jumlah populasinya. 


\section{Analisis Kompetisi Makanan}

Tumpang tindih atau niche overlap terjadi apabila terdapat dua jenis ikan atau lebih memanfaatkan sumberdaya makanan yang sama. Nilai tumpang tindih relung makanan menunjukkan adanya kesamaan jenis makanan yang dimanfaatkan diantara kelompok ikan. Berdasarkan kebiasaan makanan dari ikan tawes, ikan mujair dan ikan nila (non KJA) maka didapatkan dendrogram sebagai berikut

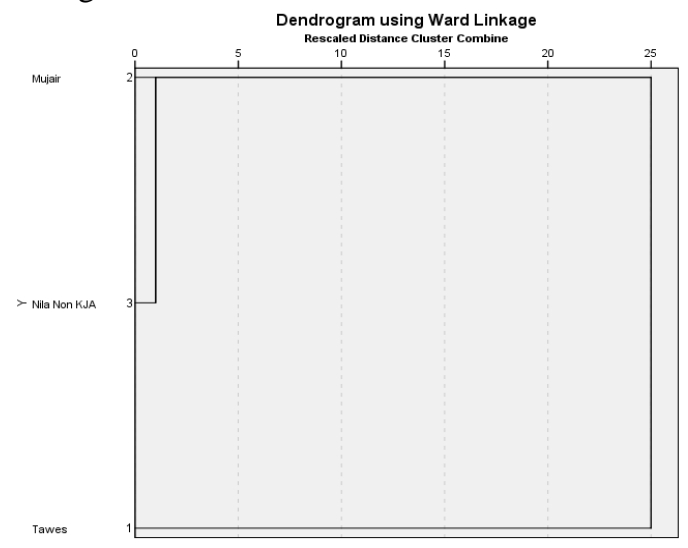

Gambar 6. Dendrogram tumpang tindih relung makanan ikan di Perairan Waduk Wadaslintang.

Berdasarkan dendrogram pada Gambar 8 menunjukkan adanya kelompok-kelompok tertentu dalam memanfaatkan pakan alami di perairan sebagai berikut :

1. Kelompok I yaitu ikan tawes dilihat dari dendrogram tidak memiliki peluang kompetisi makanan. Ikan tawes bersifat selektif dilihat dari nilai luas relungnya. Pemanfaatan makanan alami oleh ikan tawes pada beberapa jenis makanan alami yang tersedia cukup selektif. Pemanfaatan kelas Bacillariophyceae oleh ikan tawes mencapai $70 \%$

2. Kelompok II yaitu ikan mujair dan ikan nila (non KJA) memiliki peluang kompetisi yang tinggi karena pada pemanfaatan makanan alaminya, ikan mujair dan ikan nila (non KJA) sama-sama memanfaatkan kelas Bacillariophyceae sebagai makanan utamanya.

Ikan tawes merupakan salah satu jenis ikan yang selektif terhadap makanannya sedangkan ikan nila (non KJA) dan ikan mujair merupakan jenis ikan yang bersifat generalis terhadap makanannya. Menurut Sulistiono et.al (2009), perubahan proporsi dasar makanan yang dikonsumsi apabila antar kedua ikan tidak memiliki ukuran tubuh yang sama. Besarnya nilai tumpang tindih tidak berindikasi terjadinya kompetisi, namun tidak menghilangkan kemungkinan adanya kompetisi antar kedua jenis ikan yang dimaksud. Nilai tumpang tindih yang tinggi juga bisa diakibatkan oleh kelimpahan jenis organisme yang dominan di perairan.

\section{KESIMPULAN}

Kesimpulan yang didapatkan dari penelitian ini aadalah sebagai berikut :

1. Berdasarkan hasil dari nilai Index of Preponderance diketahui bahwa kebiasaan makan ikan tawes, ikan mujair dan ikan nila yang ditemukan di perairan Waduk Wadaslintang tergolong herbivora dengan makanan utamanya adalah fitoplankton. Ikan tawes, ikan mujair dan ikan nila di luar KJA memanfaatkan kelas Bacillariophyceae sebagai makanan utama. Ikan nila di dalam KJA lebih memanfaatkan makanan utama yang berasal dari kelompok makanan tidak teridentifikasi yang diduga adalah pakan buatan (pellet), namun masih memanfaatkan pakan alami yang ada.

2. Kelimpahan plankton yang ada di perairan Waduk Wadaslintang berkisar antara 424-8376 ind/L. Jenis plankton yang terdapat di perairan Waduk Wadaslintang adalah kelas Bacillariophyceae, kelas Chlorophyceae, kelas Cyanophyceae, kelas Xantophyceae dan kelas Zygnematophyceae.

3. Berdasarkan hasil perhitungan luas relung dan tumpang tindih terdapat beberapa kelompok-kelompok ikan dalam memanfaatkan pakan alami di perairan. Berdasarkan pengelompokannya, ikan nila (non KJA) dan ikan mujair merupakan kelompok ikan yang memiliki peluang kompetisi makan yang tinggi karena sama-sama memanfaatkan kelompok makanan yang sama besar dan merata.

\section{Ucapan Terimakasih}

Ucapan terimakasih ditujukan kepada Tuhan YME yang telah memberikan kelancaran sehingga penulis dapat menyelesaikan tulisan ini. Selanjutnya ucapan terimakasih juga ditujukan kepada penguji Dr. Ir. Suradi Wijaya Saputra, MS yang telah memberikan kritik dan sarannya guna untuk menyempurnakan artikel ini.

\section{Daftar Pustaka}


Anisa, Y., A. Zulfikar, T. S. Raza'i. 2015. Kebiasaan Makanan Ikan Tamban (Sardinella fimbriata) di Desa Malang Rapat Kabupaten Bintan Provinsi Kepulauan Riau. Volume 2 Nomor 1 Halaman 1-11.

Belcher, H. dan E. Swale. 1976. A Beginner's Guide to Freshwater Algae. H.M. Stationary Office

Edmondson, W. T. 1959. Fresh Water Biology. John Wiley \& Sons, Inc. USA

Effendie, M. I. 1997. Biologi Perikanan. Yayasan Pustaka Nusatama, Yogyakarta.

Elinah, D. T. F. L. Batu, Y. Ernawati. 2016. Kebiasaan Makan dan Luas Relung Ikan-Ikan Indigenous yang Ditemukan di Waduk Penjalin Kabupaten Brebes, Jawa Tengah. Volume 21 Nomor 2 Halaman 98-103.

Fatah, K dan S. Adjie. 2015. Struktur Tingkat Trofik Komunitas Ikan di Waduk Wadaslintang Kabupaten Wonosobo, Jawa Tengah. Jurnal Bawal. Volume 7 Nomor 3 Halaman 155-163.

Ghufron, M. dan H. Kordi. 2005. Budidaya Ikan Laut di Keramba Jaring Apung. Rineka Cipta, Jakarta.

Hedianto, D. A., K. Purnomo, A. Warsa. 2013. Interaksi Pemanfaatan Pakan Alami Oleh Komunitas Ikan di Waduk Penjadlin, Jawa Tengah. Jurnal Bawal. Volume 5 Nomor 1 Halaman 33-40.

Nurfadillah, A. Damar, E. M. Adiwilaga. 2012. Komunitas Fitoplankton di Perairan Danau Laut Tawar Kabupaten Aceh Tengah, Provinsi Aceh. Jurnal Depik. Volume 1 Nomor 2 Halaman 93-98.

Pratiwi, N. T. M., S. Hariyadi, I. P. Ayu, A. Iswantari, F. J. Amalia. 2013. Komposisi Fitoplankton dan Status Kesuburan Perairan Danau Lido, Bogor-Jawa Barat Melalui Beberapa Pendekatan. Jurnal Biologi Indonesia. Volume 9 Nomor 1 Halaman 111-120

Setijaningsih, L. 2011. Keanekaragaman Plankton Pada Budidaya Ikan Nila Best (Oreochromis niloticus) dengan Penambahan C-Organik. Volume 1 Nomor 1 Halaman 101-111.

Simbolon, Domu, M. F. A. Sondita, Amiruddin. 2010. Komposisi Isi Saluran Ikan Teri (Stolephorus spp.) di Perairan Barru, Selat Makassar. Jurnal Ilmu Kelautan. Volume 15 Nomor 7 Halaman 7-16.

Sulardiono, B. 2009. Analisis Dampak Budidaya Ikan Sistem Karamba Jaring Apung Terhadap Tingkat Saprobitas Perairan di Waduk Wadaslintang Kabupaten Wonosobo. Pena Akuatika. Volume 1 Nomor 1 Halaman 55-63.

Sulistiono, N. T. Tirta, M. Brodjo. 2009. Kebiasaan Makanan Ikan Kresek (Thryssa mystax) di Perairan Ujung Pangkah, Jawa Timur. Jurnal Iktiologi Indonesia. Volume 9 Nomor 1 Halaman 35-48.

Tresna, L. K., Y. Dhahiyat, T. Herawati. 2012. Kebiasaan Makanan dan Luas Relung Ikan di Hulu Sungai Cimanuk Kabupaten Garut, Jawa Barat. Jurnal Perikanan dan Kelautan. Volume 3 Nomor 3 Halaman 163-173.

Widyastuti, Endang, Agatha S.P., Diana R. U. S. R. 2009. Monitoring Status Daya Dukung Perairan Waduk Wadaslintang Bagi Budidaya Keramba Jaring Apung. Jurnal Manusia dan Lingkungan. Volume 16 Nomor 3 Halaman 133-140. 